\title{
Tarım Bilimlerinde Paradigma Değișimi: Endüstriyel Tarım ve Küresel Adalet Sorunu
}

\author{
Recep Külcü̈ ${ }^{1,2 *}$ \\ ${ }^{1}$ Isparta Uygulamalı Bilimler Üniversitesi Ziraat Fakültesi Tarım Makinaları ve Teknolojileri Mühendisliği Bölümü, Isparta, Türkiye, (ORCID: 0000-0002-7185- \\ 6514), recepkulcu@isparta.edu.tr \\ ${ }^{2}$ Akdeniz Üniversitesi, Sosyal Bilimler Enstitüsü, Felsefe ABD (Yüksek Lisans ve Doktora), Antalya, Türkiye
}

(İlk Geliş Tarihi 2 Ekim 2021 ve Kabul Tarihi 6 Aralık 2021)

(DOI: $10.31590 /$ ejosat.1003757)

\begin{abstract}
ATIF/REFERENCE: Külcü, R. (2021). Tarım Bilimlerinde Paradigma Değişimi: Endüstriyel Tarım ve Küresel Adalet
\end{abstract} Sorunu. Avrupa Bilim ve Teknoloji Dergisi, (31), 429-433.

\section{$\ddot{O} z$}

Endüstriyel tarım, tarımda verimliliği arttırmaya konsantre olmuş ve bu hedef doğrultusunda farklı teknik ve teknolojilerin kullanıldığı bir tarım yöntemini ifade etmektedir. Yirminci yüzyılın ikinci yarısından itibaren dünyanın büyük tarımsal üreticileri geleneksel tarımdan endüstriyel tarım yöntemlerine geçiş yapmışlardır. Endüstriyel tarımda geleneksel yöntemlerden farklı olarak verimliliği arttıran uygulamalar; kimyasal gübreler, tarım ilaçları, yeni ıslah teknikleri, genetiği değiştirilmiş organizmalar ve tarımda ileri teknoloji kullanımı olarak sıralanabilir. Bu uygulamaların bitkisel üretimde birim alandan alınan ürün miktarını ve hayvancılıkta et, süt ve yumurta verimlerini arttırdığı bir gerçektir. Endüstriyel tarım uygulamalarını kullanan üreticiler ve küresel tarım şirketleri amaçlarının; dünyada gıda talebini karşılamak ve doğal kaynakların tüketimini azaltmak olarak ileri sürmektedirler.

Günümüzde verimlilikte ve toplam üretim miktarlarında sağlanan onca artışa rağmen dünyada açlığın azalmadığı, buna karşın kaynakların dağılımındaki adaletsizliğin arttığı gözlenmektedir. Örneğin Birleşmiş Milletler Tarım Ajansı (FAO) istatistiklerine göre 1961-2018 yılları arasında ABD'de kişi başına yıllık et ürünleri tüketimi yılda 88-123 kg iken bu değer AB'de 51-84 kg ve az gelişmiş ülkelerde ise $9-13 \mathrm{~kg}$ arasında değişmektedir. Bitkisel ürünlerde de dağılım benzer seviyelerdedir. Bu veriler ışı̆̆ında endüstriyel tarımın ortaya çıkardığı artı değer ile gelişmiş ülkeleri pazar haline getirdiği açığa çıkmaktadır.

$\mathrm{Bu}$ çalışmada, tarım tarihinde gerçekleştirilen bilimsel gelişmeler sonucunda yeni bir paradigma olarak karşımıza çıkan endüstriyel tarım ve onu geliştiren küresel tarım sisteminin, tarımsal üretimde meydana getirdiği dönüşümler ve küresel gıda dağılımında yarattığı sorunlar incelenmiştir. Endüstriyel tarımın gelişmesiyle birlikte tarım, küresel sistem için farklı bir sermaye kaynağına dönüşmeye başlamıştır. Yeni paradigma dünya üzerinde gıda ürünlerinin paylaşımı bağlamında küresel bir adalet sorununu ortaya çıkartmıştır. Mevcut paradigmanın aynı eksende ilerlemesi durumunda dünyada açlık sorununun ortadan kaldırılamayacağı, aksine derinleştireceği açıktır. Bu nedenle, endüstriyel tarımla birlikte sağlanan ilerlemelerin yanında ürünlerin adil dağılımı ve doğal kaynakların korunması hassasiyetlerinin göz önünde bulundurulması, insanlığın uygarlık değerlerinin yükseltilmesi ve tüm insanlar için daha adil bir dünyanın ortaya çıkartılabilmesi açısından önem taşımaktadır.

Anahtar Kelimeler: Endüstriyel Tarım, Tarım Tarihi, Küresel Tarım, Etik, Küresel Adaletsizlik.

\section{Paradigm Shift in Agricultural Sciences: Industrial Agriculture and the Problem of Global Justice}

\begin{abstract}
Industrial agriculture focuses on increasing productivity in agriculture and refers to an agricultural method in which different techniques and technologies are used in line with this goal. Since the second half of the twentieth century, the world's major agricultural producers have switched from traditional farming to industrial farming methods. Applications that increase productivity unlike traditional methods in industrial agriculture; chemical fertilizers, pesticides, new breeding techniques, genetically modified organisms and the use of advanced technology in agriculture. It is a fact that these practices increase the amount of product taken from the unit area in plant production and the meat, milk and egg yields in animal husbandry. Producers and global agricultural companies using industrial agricultural practices; They argue that meeting the food demand in the world and reducing the consumption of natural resources.

Today, despite all the increases in productivity and total production, it is observed that hunger in the world has not decreased, but the injustice in the distribution of resources has increased. For example, according to the statistics of the Food and Agriculture Organization of the United Nations (FAO), while the annual per capita consumption of meat products was 88-123 kg in the USA
\end{abstract}

*Sorumlu Yazar: recepkulcu@,isparta.edu.tr 
between 1961 and 2018, this value varies between 51-84 kg in the EU and 9-13 kg in underdeveloped countries. Distribution in herbal products is at similar levels. In this context, industrial agriculture has turned developed countries into markets with the added value it has created.

In this study, industrial agriculture, which emerged as a new paradigm as a result of scientific developments in the history of agriculture, and the global agricultural system that developed it, the transformations in agricultural production and the problems it created in global food distribution were examined. With the development of industrial agriculture, agriculture has begun to transform into a different source of capital for the global system. The new paradigm has revealed a global justice problem in the context of the sharing of food products around the world. It is clear that if the current paradigm advances on the same axis, the problem of hunger in the world will not be eliminated, on the contrary, it will deepen. For this reason, it is important to consider the sensitivities of the fair distribution of products and the protection of natural resources, as well as the progress made with industrial agriculture, in order to raise the civilizational values of humanity and to create a fairer world for all people.

Keywords: Industrial Agriculture, History of Agriculture, Global Agriculture, Ethics, Global Injustice.

\section{Giriş}

Tarım devrimi günümüzden yaklaşık 10000 yıl önce bazı bitki türlerinin kültüre alınması ve hayvanların evcilleştirilmesiyle başlamıştır (Toffler, 2008: 22). Tarım devrimiyle birlikte insanlar toplum hayatına geçmişler ve küçük yerleşim alanlarında tarımsal üretim gerçekleştirmeye başlamışlardır. Tarım devriminden günümüze kadar tarımsal üretim farklı aşamalardan geçmiştir. Bu aşamalar Şekil 1'de gösterildiği gibi gruplandırılabilir (Külcü, 2021: 5; Kayacan vd., 2021; 681)

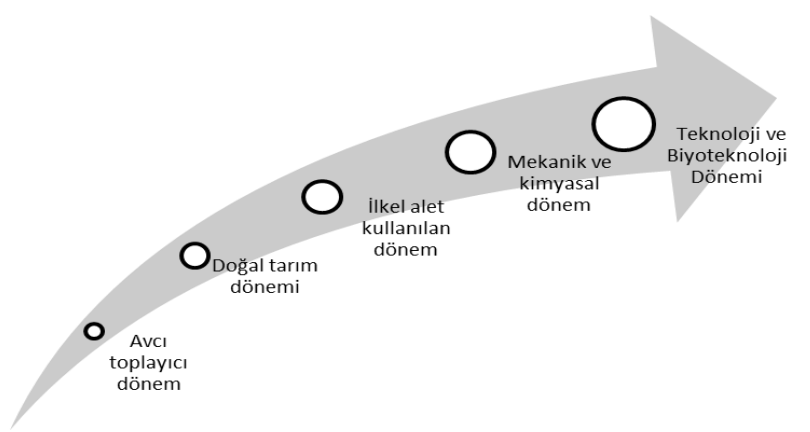

\section{Şekil 1. Tarım Bilimlerinin Evrimi}

Avcı-toplayıcı dönemde insanlar doğaya müdahale etmeden onun kendisine sunduğu besinleri toplayarak veya hayvanları avlayarak gıda ihtiyacını karşılamaktaydı. Bu dönemde henüz tarım devrimi gerçekleştirilmemiştir fakat tarım devrimini gerçekleştirmek için gerekli olan bilgi ve tecrübe bu dönemde edinilmiştir. Doğal tarım döneminde insanlar doğaya çok fazla müdahale etmeden, belirli alanlarda tohumları ekmiş ve tarımsal üretimi başlatmıştır. $\mathrm{Bu}$ dönem tarım devriminin başlangıcı olarak kabul edilebilir. İlkel alet kullanılan dönemde insanlar tarımsal üretim için doğaya müdahaleler yapmaya başlamış ve toprağın tohum gelişimi için uygun hale getirilmesi için ilkel toprak işleme aletleri kullanılmaya başlanmıştır. $\mathrm{Bu}$ dönemde temel güç kaynağı olarak insan ve hayvan gücü kullanılmıştır. Mekanik ve kimyasal dönem sanayi devrimi sonrasında tarımda termik motorların kullanıldığı, özel tarım makinalarının geliştirildiği, bitki besleme ve bitki koruma kimyasallarının kullanılmaya başlandığı dönemi ifade etmektedir. Teknoloji ve biyoteknoloji dönemi ise tarımda bilişim sistemlerinin kullanıldığı, radyasyon ıslahı ve genetiği değiştirilmiş organizmaların geliştirildiği tarım dönemine karşılık gelmektedir. Tarım bilimlerinin gelişimini ifade eden bu dönemlerden mekanik ve kimyasal dönem, endüstriyel tarıma geçişin olduğu aşamadır ve birinci yeşil devrim olarak adlandırılmaktadır. Teknoloji ve biyoteknoloji dönemi ise ikinci yeşil devrimin gerçekleştirildiği aşamadır.

\section{Yeşil Devrim ve Endüstriyel Tarımın Gelişimi}

Endüstriyel tarım uygulamaları için yeşil devrim ifadesinin kullanılması 1940'lı yıllarda başlamıştır. Rockefeller Vakfı ve Meksika hükümetinin 1943 yılında özel çalışmalar ofisini kurması bu ofiste yeni buğday ve mısır çeşitleri geliştirmesiyle yeşil devrimin ilk adımları atılmıştır. Bu ofis 1963 yılında CIMMYT (Uluslararası Mısır ve Buğday Geliştirme Merkezi) adını almıştır. Bitkilerde gerçekleştirilen bu çalışmalar hayvancılıkta ıslah ve GDO (Genetiği Değiştirilmiş Organizma) faaliyetleri olarak gerçekleşmiştir. Yirminci yüzyılın sonlarında tarımda "İkinci Yeşil Devrim” adı verilen dönüşüm gerçekleşmiştir. $\mathrm{Bu}$ devrimle, canlılar arasında gen transferleri olarak adlandırılan GDO (Genetiği Değiştirilmiş Organizma) çalışmaları başlamıştır (Atalık, 2010: 4; Şahinöz, 1980: 234; Nur vd., 2016)

\subsection{Endüstriyel Tarımda Verim Artışı}

Endüstriyel tarım birinci ve ikinci yeşil devrimle tarımda ürün çeşitliliğini ve üretim miktarlarını hızla arttırmıştır. Şekil 2 ve Şekil 3'de dünyada temel besin kaynağı olarak kabul edilen tahıllar olan buğday ve mısır bitkilerinin 1961-2019 yılları için verim değerlerindeki değişimler gösterilmiştir. Dünya ortalamasında 1961 yılında bir hektar tarım arazisinden 10889 hg (yaklaşık 1 ton) buğday alınabilirken, bu değer 2019 yılında 3.25 kat artarak $35468 \mathrm{hg}$ (yaklaşı 3.54 ton) seviyesine yükselmiştir. Buğday verimleri 2019 yılında ABD'de bir hektar tarım arazisinden 34748 hg (yaklaşık 3.47 ton), Avrupa Birliği ülkelerinde $59802 \mathrm{hg}$ (yaklaşı 5.97 ton) seviyelerine yükselmiştir.

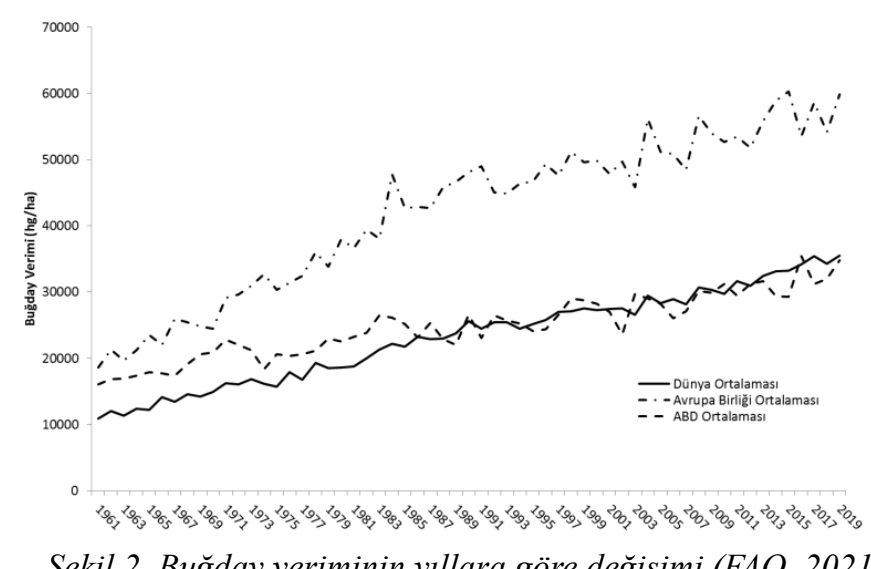

Şekil 2. Buğday veriminin yıllara göre değişimi (FAO, 2021) 
Dünyada mısır verimlerinde de buğdaya benzer artışların sağlandığı görülmektedir. Dünya ortalamasında bir hektar tarım arazisinden 1961 yılında $19432 \mathrm{hg}$ (yaklaşı 1.94 ton) misır üretilirken bu değer 2019 yılında 2.99 kat artarak 58238 hg (yaklaşık 5.82 ton) seviyesine yükselmiştir. 2019 yılında Avrupa Birliği Ülkelerinde bir hektar tarım arazisinden 78605 hg (yaklaşık 7.86 ton) ve ABD’de 105323 hg (yaklaşık1.05 ton) mısır üretilmiştir.

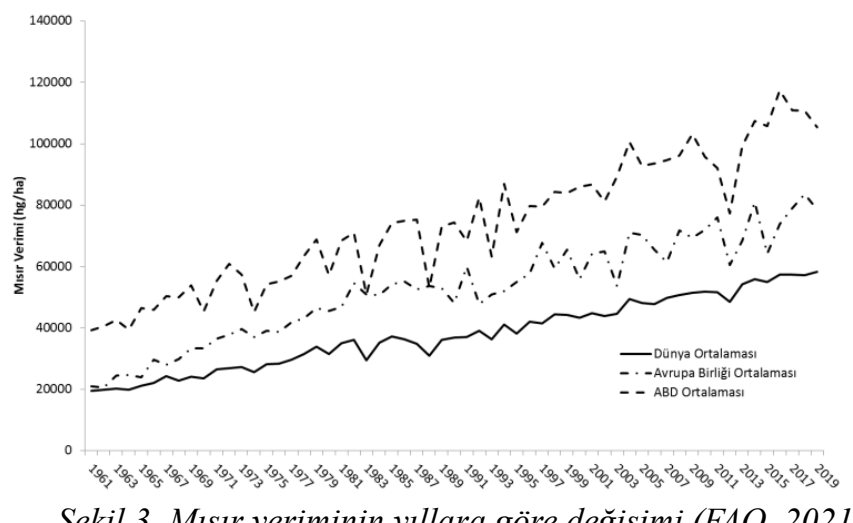

Şekil 3. Misır veriminin yıllara göre değişimi (FAO, 2021)

Endüstriyel tarım uygulamaları hayvancılık sektöründe de önemli değişiklikler gerçekleştirmiştir. Şekil 4'de Amerika Birleşik Devletleri'nde bir süt sığırından alınan süt miktarının yıllara göre değişimi gösterilmiştir. Amerika Birleşik Devletleri'nde bir süt sığırından 1900 yılında 2000 kg'dan daha az süt alınırken bu rakam 1970'li yıllarda iki katına çıkarak 4000 kg seviyelerine yükselmiş ve 2000 yılında 8000 kg'ın üzerine çıkmıştır. Günümüzde bir süt sığırından yılda alınan süt miktarı 10000 kg'ın üzerindedir.

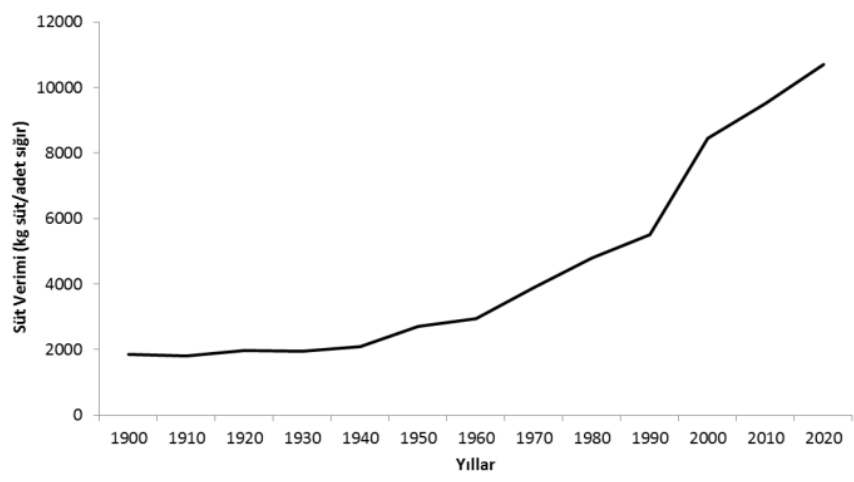

Şekil 4. Amerika Birleşik Devletlerinde süt sığırların yıllık süt verimleri (STATISCA, 2021; VandeHaar ve Pierre, 2006: 1280)

\section{Dünyada Gıda Tüketim İstatistikleri ve Açlık Sorunu}

Buğday, mısır ve süt verimlerindeki artışların temel nedeni endüstriyel tarım uygulamalarıdır. Tarımsal üretim bağlamında endüstriyel tarımın hedeflerine ulaştığı ve verimliliği arttırmayı başardığı olgusal bir gerçektir. Fakat endüstriyel tarımın uyguladığı yöntemlerle arttırılan tarımsal üretimin hangi amaçlarla kullanıldığı da tartışılması gereken bir durumdur. Tarımın temel amacı insanların gıda ihtiyaçlarının karşılanması, tekstil ve tarıma dayalı sanayi işlemleri için hammadde üretilmesidir. Şekil 5'de dünyada az gelişmiş ülkeler ile ABD ve Avrupa Birliğine üye ülkelerde yaşayan insanların günlük buğday ürünleri tüketiminin yıllara göre değişimi gösterilmiştir. Kişi başına yıllık buğday ürünleri tüketimi az gelişmiş ülkelerde
15-32 kg aralığında değişirken bu tüketim değeri ABD'de 65-81 $\mathrm{kg}$ ve $A B$ 'de $97-111 \mathrm{~kg}$ aralığındadır. Buğday ürünleri tüketimi bağlamında az gelişmiş ülkelerde yaşayan insanlar ile ABD ve $\mathrm{AB}$ ülkelerinde yaşayan insanlar arasında ciddi bir farkın olduğu görülmektedir.

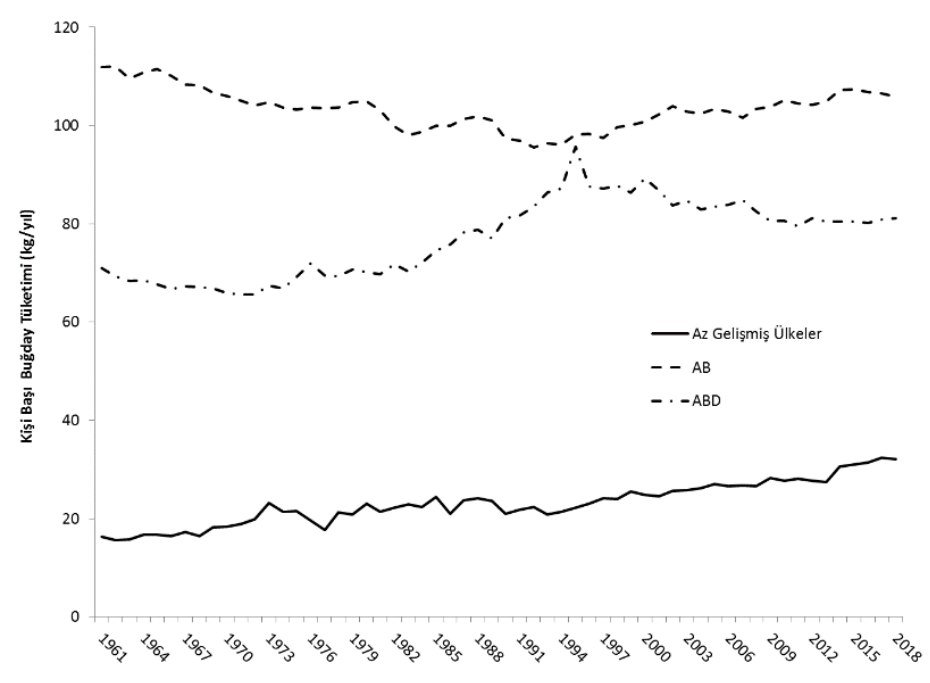

Şekil 5. Kişi başına yıllık buğday tüketim miktarları (FAO, 2021)

Şekil 6'da az gelişmiş ülkeler, ABD ve AB topraklarında yaşayan insanların yıllık et ürünleri tüketim miktarlarının yıllara göre değişimleri gösterilmiştir. Az gelişmiş ülkelerde yaşayan insanların yıllık et ürünleri tüketim miktarı ortalaması 9-13 kg arasında değişirken bu seviye AB'de 51-84 kg ve ABD'de 88$123 \mathrm{~kg}$ arasında değişim göstermiştir. Yıllık ortalama et tüketim miktarı seviyeleri az gelişmiş ülkeler ile $A B D$ ve $A B$ ülkeleri arasında ciddi bir uçurumun olduğuna işaret etmektedir.

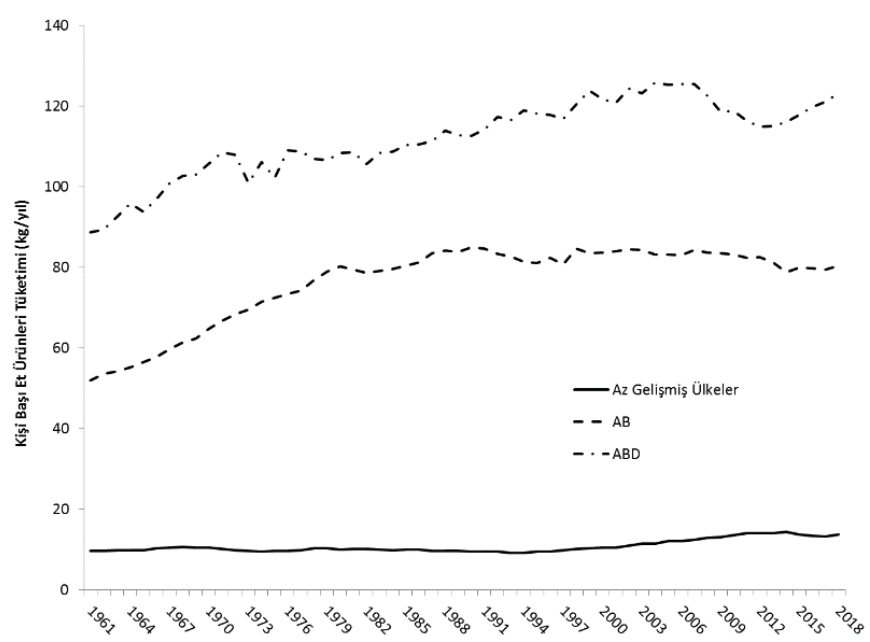

Şekil 6 Kişi başına yıllık et ürünleri tüketim miktarları (FAO,

Şekil 7'de Az gelişmiş ülkeler, ABD ve AB üyesi ülkelerde yaşayan insanların bir günde aldıkları bütün gıdaların enerji içeriklerinin ortalamalarının değişimi gösterilmiştir. Az gelişmiş ülkelerde yaşayan insanların gıda yoluyla aldıkları günlük enerji ortalaması 1950-2407 kcal/kişi/gün aralığında değişirken, bu değer $\mathrm{AB}$ üyesi ülkelerde 3000-3450 kcal/kişi/gün ve ABD'de 3000-3800 kcal/kişi/gün seviyelerindedir. İnsanların metabolizma ve günlük faaliyetleri için ihtiyaç duydukları enerji miktarları 2250-2800 kcal/gün aralığındadır (Pardey vd., 2014: 578; Sayan, 1999). Dünyada besinlerden alınan günlük enerji değerlerinin ortalamaları incelendiğinde; az gelişmiş ülke 
ortalamalarının sınırın biraz altında, $A B D$ ve $A B$ üyesi ülkelerin ortalamalarının ise sınırın üzerinde olduğu görülmektedir. $\mathrm{Bu}$ durum gelişmiş ülkelerde gidanın yaşamsal bir ihtiyaç olmaktan çıktığı ve gereğinden fazla tüketim yoluyla obezite gibi sorunların kaynağı olduğuna işaret ederken, gelişmemiş ülkelerde açlık riskinin bulunduğunu göstermektedir. Ancak ortalama değerler içerisindeki standart sapmanın boyutu bu ortalama değerler içerisinde aç kalan insanların görünmesini zorlaştırmaktadır.

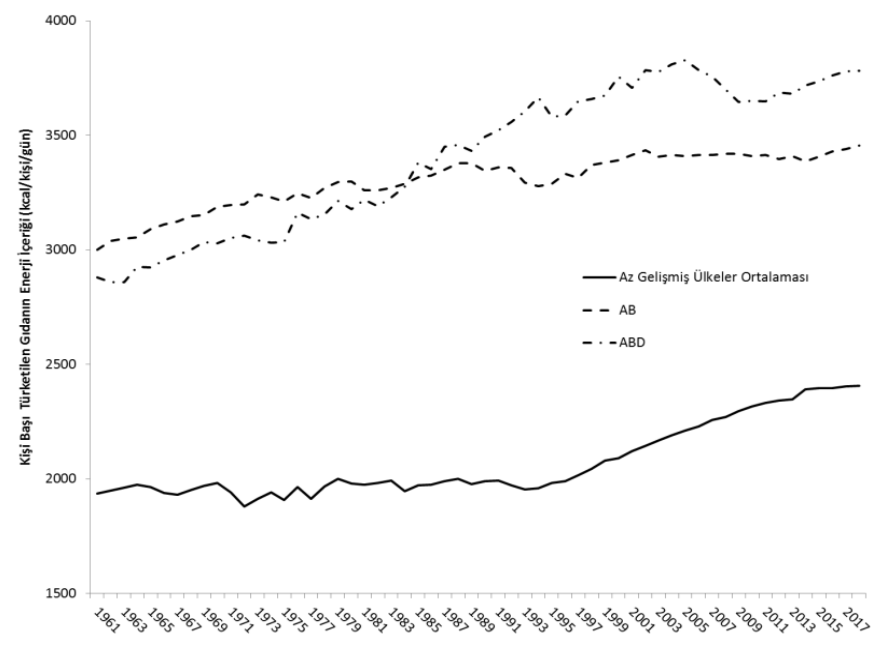

Şekil 7. Kişi başına günlük gıda yoluyla alınan enerji miktarları (FAO, 2021)

Şekil 8'de dünyada yetersiz beslenen insan sayılarının değişimi gösterilmiştir. Dünyada yetersiz beslenen veya besine ulaşamayan insan sayısı 2000 yılında 800 milyon seviyesindeyken bu rakam 2020 yılına kadar istikrarsız bir seyir izleyerek 768 milyon olarak gerçekleşmiştir. Ayrıca 927 milyon insan gıdaya düzenli olarak ulaşamamaktadır. Dünyada gıda üretiminin artmasına rağmen yetersiz beslenen insan sayılarının kararlı bir şekilde azalmaması, açlıkla mücadele bağlamında bir iradenin tam olarak oluşmadığını göstermektedir.

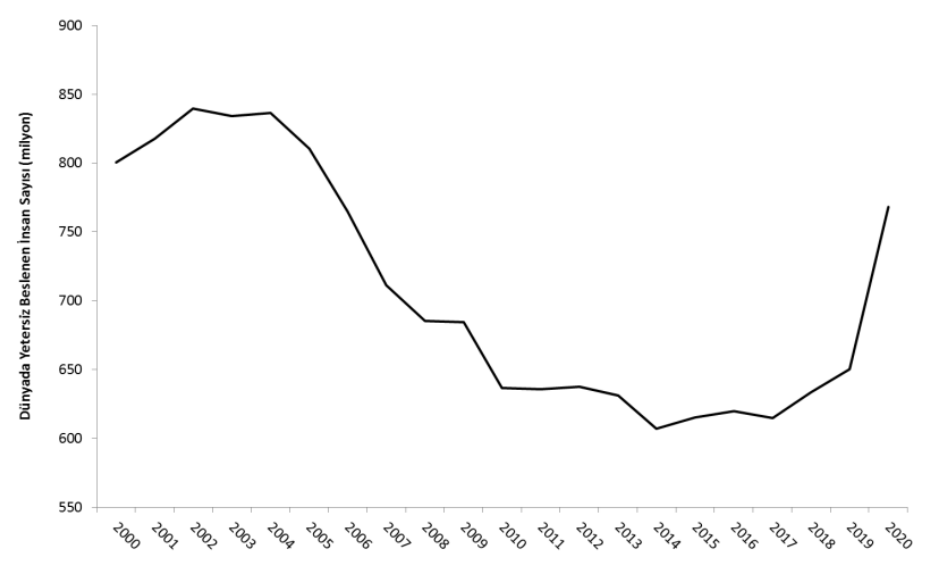

\section{Şekil 8. Dünyada yetersiz beslenen insan sayısının yıllara göre} değişimi (FAO, 2021)

Şekil 9'da dünyanın farklı bölgelerinde gıdaya ulaşamayan yani açlık yaşayan insan oranları gösterilmiştir. Dünyada açlık yaşayan insan oranı \%9.9'dur. Afrika'nın \%21'i, Güney Amerika'da yaşayan insanların \%7.8'i ve Okyanusya'da yaşayan insanların \%6.2'si açlık içerisinde yaşamaktadır.

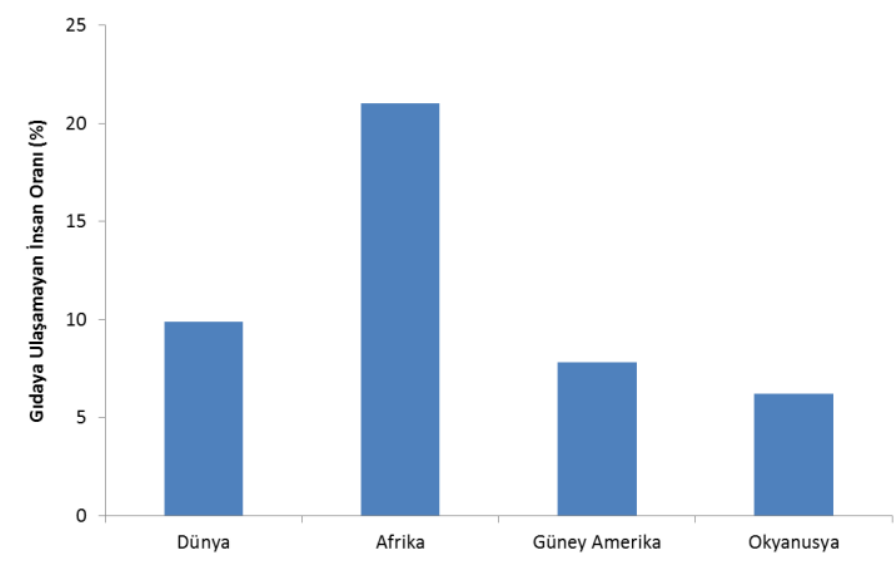

Şekil 9. Dünya'nın farklı kıtalarında gıdaya ulaşamayan insan oranlart (FAO, 2021)

\section{Sonuç}

Tarım insanlık tarihinde uygarlığın başlamasını sağlayan ve artan nüfusun besin ihtiyacını karşılayan bir faaliyet alanı olarak stratejik öneme sahiptir. Normatif etik kuramları içerisinde deontolojik bir yaklaşım ortaya konduğunda, tarımın evrensel görevinin insalığın gıda ihtiyacının karşılanması olduğu söylenebilir. Teleolojik etik kuram açısından da tarımsal uygulamaların insanlığın çoğunluğunun faydası için yapılması gerektiği ortaya çıkmaktadır. Tarımsal üretim, günümüzden on bin yıl önce gerçekleşen tarım devriminden günümüze kadar birçok değişim ve dönüşüm göstermiştir. Tarımın gelişim süreci birim alandan alınan verimin arttırılması doğrultusunda büyük ilerlemeler sağlamıştır. Bu ilerlemeler, tarım bilimleri alanında gerçekleştirilen teknolojik ve bilimsel çalışmaların katkısıyla ortaya çıkartılmıştır. $\mathrm{Bu}$ bağlamda tarım bilimleri alanında yapılan çalışmaların deontolojik ve teleolojik kuramlar açısından uygun olduğu söylenebilir. Yirminci yüzyılın ikinci yarısından itibaren gerçekleşen gelişmeler tarım sektöründe yeni bir paradigmanın ortaya çıkmasına neden olmuştur. Yeni paradigma içerisinde endüstriyel tarım adı verilen bir üretim modeli yaygınlaşmaya başlamıştır. Yeni paradigma içerisinde üretim miktarları arttırılırken, tarımın deontolojik bağlamda temel hedefi veya ödevi olan insanlığın gıda ihtiyacının karşılanması bağlamında etik bir sorununun ortaya çıktığı görülmektedir. Endüstriyel tarımın gelişmesiyle birlikte 2018 yılında kişi başına düşen gıdanın enerji miktarı 2929 kcal/kişi/gün seviyesine yükselmiştir (FAO, 2021). Bu rakam tarımsal üretimin, dünya üzerindeki tüm insanları doyuracak seviyeye ulaştığını ortaya koymaktadır. Buna rağmen dünyada yaşayan insanların \%9.9'unun açlık içerisinde yaşıyor olması, gıda üretiminin dünyada açlık sorununu gidermek yerine, küresel tarım firmalarının sermaye miktarlarını arttırma doğrultusunda gelişmiş ülkeleri pazar haline getirmeye yöneldiğini ortaya çıkartmaktadır. Birleşmiş Milletler Tarım Ajansı'nın istatistiksel verileri; insanlığın tarım devrimiyle kurduğu uygarlığı, mevcut küresel sistemde, yoksulluk ve açlık çeken insanları görmezden gelerek yükseltmeyi tercih ettiğine işaret etmektedir. Bu noktada endüstriyel tarım yöntemleri üzerinde şekillenen ve küresel tarım şirketlerinin yönlendirmesiyle ortaya çıkan yeni paradigmanın deontolojik ve teleolojik açıdan tarımın etik ilkelerine aykırı olduğu açıktır. Elbette yeni tarım teknik ve teknolojilerinin geliştirilmesi ile tarımda verimliliğin arttırılması büyük bir öneme sahiptir. Fakat endüstriyel tarımla birlikte ortaya çıkan paradigmanın, dünya üzerinde yaşayan bütün insanların refahının arttırılması ve tarımsal ürünlerin adil dağılımı 
hassasiyetleri gözetilerek yeniden şekillendirilmesi daha etik ve sürdürülebilir bir dünya kurulması açısından büyük bir öneme sahiptir.

\section{Kaynakça}

Atalık, A. (2010). İkinci Yeşil Devrim GDO'lar ve Sonrası Tufan. Görünmez Elin Ekolojisi Biyogüvenlik ve GDO, TMMOB Ziraat Mühendisleri Odası Ankara.

FAO. (2021). Agricultural Statistics. Erişim Adresi: http://www.fao.org/faostat/en/. Erişim Tarihi: 12/09/2021.

Kayacan, T., Özel, Y., Kayacan, B. (2019). Kente Kazandırılan Yeni Yaşam Alanları. Avrupa Bilim ve Teknoloji Dergisi, (16), 679-687.

Külcü R. (2021). Tartm Etiği Demokritos 'tan Leopol'da Islahtan GDO'ya. Nobel Bilim Yayınevi, İstanbul.

Nur, G., Deveci, H., Kırpık, M. A. , Nur, Ö., Bağrıaçık, N. \& Yıldız, Y. (2016). Sürdürülebilir Üretim Yaklaşımı: Ekolojik Tarım. Kafkas Üniversitesi Fen Bilimleri Enstitüsü Dergisi, 9 (2), 3-8.

Pardey, P.G., Beddow, J.M., Hurley, T.M., Beatty, T.K.M. Eidman, V.R.. (2014). A Bounds Analysis of World Food Futures: Global Agriculture Through To 2050 Aust. J. Agric. Resour. Econ., 58, pp. 571-589, 10.1111/1467-8489.12072

Sayan, A. 1999. Beslenme Alı̧skanlıkları ve Temel Besin Gereksinimleri. Atatürk Üniversitesi Hemşirelik Yüksekokulu Dergisi 2 (2).

STATISCA. (2021). Amerika Birleșik Devletlerinde süt üretim istatistikleri. Erişim adresi: https://www.statista.com/statistics/194935/quantity-of-milkproduced-per-cow-in-the-us-since-1999/, erişim tarihi: $09 / 09 / 2021$.

Şahinöz, A. (1990). Yeşil Devrim ve Açlık Sorunu . Hacettepe Üniversitesi Iktisadi ve İdari Bilimler Fakültesi Dergisi, 8 (1).

Toffler, A. (2008). Üçüncü Dalga. (çev. S. Yeniçeri), Koridor Yayıncıllk, İstanbul.

VandeHaar, M. J. and StPierre, N. (2006). Major Advances in Nutrition: Relevance to the Sustainability of the Dairy Industry Journal of Dairy Science, Vol. 89 (4), 1280. 